\title{
MONITORING AGRICULTURAL CONDITIONS IN RURAL AFGHANISTAN
}

Submitted to: Ofice of the AID Representative for Afghan Afriv

Islamabad, Pakistan

\author{
Wmiam D. Drake
}

Juky 1986

Commonity Systems Formdation

$\because$

Ann Arbor, MI 48104 U.S.A.

Tel: (313) 761-1357

Telex: 759414 


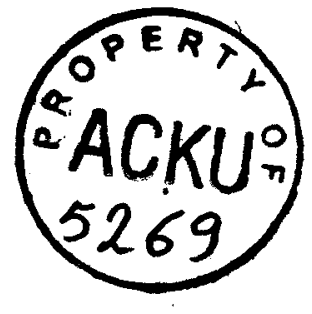

\title{
MONITORING AGRICULTURAL CONDITIONS IN RURAL AFGANISTAN
}

Submitted to: Office of the AID Representative for Afghtm Affairs

Islamabad, Rakistan

\author{
William D. Drake
}

July 1986

Community Systems foimutation

1130 Hill Strest

Ann Arbor, MI 48104 U.S.A.

Tel: (313) 761-1357

Telex: 759414 


\section{EXECUTIVE SUMMARY}

The Office of the AID Representative for Afghanistan Affairs is planning for the implementation of a project to monitor the agricultural conditions in rural Afghanistan. This effort is expected (1) to assist the AID/Rep in programming cross-border humanitarian assistance and (2) to better inform European donor agencies about the conditions in rural Afghanistan so that they can make informed decisions. An extremely important corollary objective is to initiate the process of institutionalizing such a system in the donor agencies.

The purpose of this two-week consultancy was to assist in the design of such a project by reviewing existing plans, to propose alternative options for conducting the effort, and to help specify the nature of the required technical assistance.

Six options were considered for meeting the two objectives mentioned before. These options ranged from survey of recent migrants in Pakistani refugee camps alone, to various configurations of surveys with farmers in Afghanistan, to attempting to gather data only from ongoing existing programs as part of their typical activities. Although this last option normally is useful and effective, it was felt that the current cross-border humanitarian assistance programs did not lend themselves to meeting both objectives. Rather an option which combined interviews in refugee camps and farmers in Afghanistan is recommended.

A package of technical assistance is suggested which allows for extremely fast feedback of data analyzed in a form which will permit immediate use by the office of the AID/REP. At the same time, the second objective, informing European donors, can be pursued on a parallel track. The key to this approach is a database management system which has error detection and correction capabilities combined with an on-site, "hands-on" training program in the use of the tool for policy analysis.

A schedule of implementation calls for 19 months elapsed time for the entire project, with the first rapid feedback analysis on a subset of the data 7 months after the start of the project and 2 months after initiation of the data gathering effort. The estimated budget for the recommended option is approximately $\$ 370,000$. 


\section{ACKNOWLEDGEMENTS}

This report is the project of a two-week consultancy (July 8-18, 1986) which built upon some careful thinking undertaken by the Office of the AID Representative for Afghanistan Affairs and the Swedish Afghanistan Committee. While I was in country, continuous substantive input was provided by Val Mahan, John Gunning, and Al Nehoda. Anders Fange and Noory Mohammad Arif of the Swedish Committee provided both useful background information and helpful suggestions.

Special thanks to Susan Hase, Jessie Clyne, and Margaret Greene for making the report happen. 


\section{TABLE OF CONTENTS}

EXECUTIVE SUMMARY $\ldots \ldots \ldots \ldots \ldots \ldots \ldots \ldots \ldots \ldots \ldots \ldots \ldots \ldots \ldots$ i

ACKNOWLEDGEMENTS $\ldots \ldots \ldots \ldots \ldots \ldots \ldots \ldots \ldots \ldots \ldots$ ii

I. INTRODUCTION $\ldots \ldots \ldots \ldots \ldots \ldots \ldots \ldots \ldots \ldots \ldots \ldots \ldots \ldots \ldots$

II. AGRICULTURAL INFORMATION $\ldots \ldots \ldots \ldots \ldots \ldots \ldots \ldots . \ldots \ldots$

A. Aid Programming Needs $\ldots \ldots \ldots \ldots \ldots \ldots \ldots \ldots \ldots \ldots \ldots$

B. European Private Voluntary Organizations' Needs . . . . . . . . . 3

C. Institutional Needs $\ldots \ldots \ldots \ldots \ldots \ldots \ldots \ldots \ldots \ldots \ldots \ldots \ldots \ldots$

D. Gathering Data in Afghanistan and Other Design Considerations . . . . 3

Figure 1 Major Areas under Cultivation in Afghanistan . . . . . . .

Figure $2 \quad$ Land Use Categories in Afghanistan . . . . . . . . . . . . . . .

Table 1 Household-Level Data . . . . . . . . . . . . . . . .

Table 2 Community-Level Data $\ldots \ldots \ldots \ldots \ldots \ldots \ldots \ldots$

III. FEASIBLE OPTIONS FOR GATHERING DATA . . . . . . . . 9

Option 1. Gather Data from Refugee Camps Only . . . . . . . . . . .

Option 2. Implement the Original Plan without Modification . . . . . . . . . 9

Option 3. Implement Original Plan but with Modified Technical Assistance ............................

Option 4. Gather Data from Afghan Medical Workers Currently Interacting with the Swedish Committee ............

Option 5. Gather Data from Mujahideen Commanders Who Visit the Swedish Committee . . . . . . . . . . . . . . . . .

Option 6. Gather Data Only from the AID Supported Programs Currently under Implementation $\ldots \ldots \ldots \ldots \ldots \ldots \ldots$

Recommended Option .......................

IV. DATA HANDLING AND ANALYSIS $\ldots \ldots \ldots \ldots \ldots \ldots$

Implementation Considerations $\ldots \ldots \ldots \ldots \ldots \ldots \ldots \ldots \ldots$

V. PHASING, TIMING, AND BUDGET CONSIDERATIONS $\ldots \ldots \ldots \ldots .15$

Figure $3 \quad$ Schedule of Project Tasks Ordered by Time . . . . . . . . . .

APPENDIX A. REFERENCE MATERIALS . . . . . . . . . . . . 17

APPENDIX B. AZUM GUL SURVEY OF $1982 \ldots \ldots \ldots \ldots \ldots \ldots \ldots \ldots$

APPENDIX C. PERSONS CONTACTED .................. 23 


\section{INTRODUCTION}

At this moment, many nations of the world are engaged in providing humanitarian assistance to the rural people of Afghanistan. This assistance is of special importance because of the recent intensification of the Soviet program to depopulate those areas of the country not under their control. In addition to military means, they have restricted commodities necessary for agricultural production together with foodstuffs not grown locally. This scarcity has raised costs or eliminated the availability of food, thereby forcing migration either to urban regions in Afghanistan or to other countries. Humanitarian assistance, therefore, is an attempt to provide some of the basic living necessities to allow these rural dwellers to continue to survive in their traditional homelands.

Monitoring agricultural conditions in rural Afghanistan has dual objectives:

1) AID Programming - to determine in which regions the need for humanitarian assistance is the greatest and what effect any assistance might have, and

2) Knowledge for Donors - to monitor the overall agricultural conditions in the rural areas so that potential donors throughout the world can be provided with credible information upon which to make decisions.

Because of the war in many of these regions, there are some approaches to gathering information which are virtually impossible due to danger or cost. In addition, a system designed to meet the first objective alone does not necessarily fulfill the needs of the second objective.

One purpose of this report, therefore, is to suggest feasible alternative options for gathering and analyzing Afghanistan agricultural data which will accomplish as well as possible both of the aforementioned objectives. The consultancy began with a review of preliminary plans prepared by the Swedish Committee in coordination with the Office of the AID Representative (O/AID/REP). Reference materials (Appendix A) were studied, several very useful discussions were held with the Director of the Swedish Committee and his key staff members in Peshawar, Pakistan, and a review of the local computational capabilities was made. Alternative options were reviewed with both the Swedish Committee and the O/AID/REP and the 6 most likely options selected for further detailing. The body of this report is divided into four additional sections as follows:

II. Agricultural Information

III. Feasible Options for Gathering Data

IV. Data Handling and Analysis

V. Phasing, Timing and Budget Considerations 


\section{AGRICULTURAL INFORMATION}

This section begins by delineating the types of information needs for both AID and the European donor community. It then presents some of the design constraints on data gathering imposed by the war and the implications for building an institutional analysis capability.

\section{A. Aid Programming Needs}

Determining which regions will receive humanitarian assistance from AID is a complex decision. It is, of course, based upon need, which could be revealed by an agricultural information system and/or other sources of information. However, it is also based upon the practicality of implementing the assistance-both logistically and politically. It is probable that these other factors will play a dominant role in some allocation decisions. In addition, because of the very high need levels, resource constraints will also play an important role.

Presently, there are three types of agriculture-related assistance programmed for Afghanistan. The first, "Cash-for-Food," is a program that provides cash for purchasing food to rural Afghans. This cash is carried into Afghanistan by several different non-US voluntary agencies. Afghanaid, a British voluntary agency, receives some of its Cash-forFood funding from AID. While the procedures for ensuring proper distribution within Afghanistan are subject to AID scrutiny, the actual records are retained by Afghanaid for security purposes. AID knows the province and in some cases the village but never the individuals. The cost per recipient varies depending upon the cost of the commodity on the local market, transportation, local administration, and organizational overhead assigned to the region being assisted. The cash provided to the recipient is sufficient to purchase 500 grams of wheat per day, thereby providing approximately 2,000 calories. Funds for tea, sugar, and oil are also provided. Afghanaid uses a simple rule-of-thumb which is somewhat arbitrary for determining the number of persons covered.

The second program type provides modest levels of assistance to European Private and Voluntary Organizations (PVOs) who are attempting to help restore production disrupted by the war. Examples of the PVOs involved in this assistance are the German Afghanistan Committee and the Austrian Relief Committee.

The third type of agriculture-related program which is about to begin is the Commodity Export Program (CEP). This program offers certain "approved" commodities to the leaders of the free areas of Afghanistan. Commodities such as fertilizers, seeds, and animals will be provided to these groups at the Pakistan border. It is the responsibility of 
the mujahideen commanders to distribute the commodities within Afghanistan. The allocation will be made through the "Seven Party" Alliance.

For all three programs, Cash-for-Food, Agriculture Assistance, and Commodity Export Program, the types of information useful for initial programming are 1) regional food deficits, and 2) scarcity of material needed for agricultural production.

\section{B. European Private Voluntary Organizations' Needs}

The informational needs of private and voluntary organizations providing humanitarian assistance to Afghanistan have considerable overlap with AID programming requirements. In fact, one of them, Afghanaid, now receives some of its support for its Cashfor-Food program from AID. However, these private and voluntary organizations have additional information needs as well. First, some of their work is in regions not covered by AID. Second, because they operate inside Afghanistan, their programming needs are more specific. Third, and perhaps most important, they wish to be able to tell the World Community about the conditions in rural Afghanistan in as credible a way as possible. Reports describing conditions in Afghanistan have been criticized because they have taken data only from migrants living in the refugee camps in Pakistan-even though these refugees are recent arrivals. Claims that they represent a highly biased sample are irrefutable in the absence of methodological procedures for adjusting these biases. Gathering data in Afghanistan will improve both the credibility and the ability to utilize refugee data.

\section{Institutional Needs}

In addition to the acquisition of agricultural information in the short run, there is a need to institutionalize this capability for the future. A strong argument can be made for institutionalizing data gathering and analysis capability by using some mechanism which is 1) not directly associated with the United States, 2) well respected and 3) if possible, Afghan in character. If such a goal is ever to be achieved, now is the time to begin. Experience elsewhere has shown that when institutions are developed without involvement of those who eventually receive them, problems arise. At the very least, these institutions are viewed with low priority and at worst are allowed to die.

\section{Gathering Data in Afghanistan and Other Design Considerations}

Gathering agricultural data inside Afghanistan is difficult and. in some cases dangerous. Many areas in the north and the central mountainous regions are completely inaccessible during the winter months. Those areas which are agriculturally productive comprise a very small percentage of the rural land mass and vary enormously in annual 
yield. Figure 1 shows the major areas under cultivation as portrayed in a 1980 text. ${ }^{1}$ Figure 2 describes agricultural land use categorized by irrigated cultivation, dry farming and grazing, forestry and sparse vegetation. Population density is largely coincident with intensity of agricultural productivity. Double cropping is largely restricted to the southern provinces of Nimruz, Helmand, Qandahar, and Zabol, and to regions east and south of Kabul.

Superimposed upon this mosaic of agricultural productivity are the effects of the war. As the war has intensified, these effects have become more pronounced. Any plan to monitor agricultural conditions, especially one relying upon sample data taken from refugees, must deal with these variations in order to be properly interpreted. Unfortunately, the most appropriate method for dealing with these problems is a random sample, which is not feasible due to war conditions. At present and into the foreseeable future it is not practical to obtain a listing of the population from which to draw the random sample. However, the country could be categorized by agricultural productivity and amount of war activity. Data sources presently exist for regional productivity and these could be made more locally specific by visits from the field staff associated with the Swedish Committee. These teams could also make an assessment of the amount of war activity and disruption by implementing a community-level field schedule. This categorization then could be used to stratify observations for later statistical adjustment. If data gathered either from refugees or from current residents of the locality were similarly classified, a quasi-experimental design could be employed to determine changes over time.

War conditions impose additional constraints upon data gathering besides accessibility to some regions. The present plan calls for sending ten teams into Afghanistan for up to five months. (Less time would be required for regions close to the Pakistan border.) Each team is expected to focus upon a single province and must be comprised of staff who are residents of that region. Otherwise, suspicions may be raised by local authorities and the interview team placed at risk. At this time it is also felt that to keep an interview team in one location for longer than a day or two also will be risky. Therefore the research design cannot assume a cluster sample at the village level in all cases. Each of the ten teams expects to be able to administer 50 interviews in at least two different districts in one province resulting in a total of 500 Afghanistan interviews during the first cycle.

Attributing the cause of changes in agricultural production and food availability is another problem altogether. Changes could be due to three basic causes: 1) war activity (both direct and indirect), 2) outside assistance (Cash-for-Food, CEP, etc.), or 3) climatic variation or shifting trends. Attributing causes to 1 or 3 above could be accommodated by direct assessment by the interview team as described earlier. However, attributing cause to

Louis Dupree, Afghanistan (Princeton University Press, 1980). 


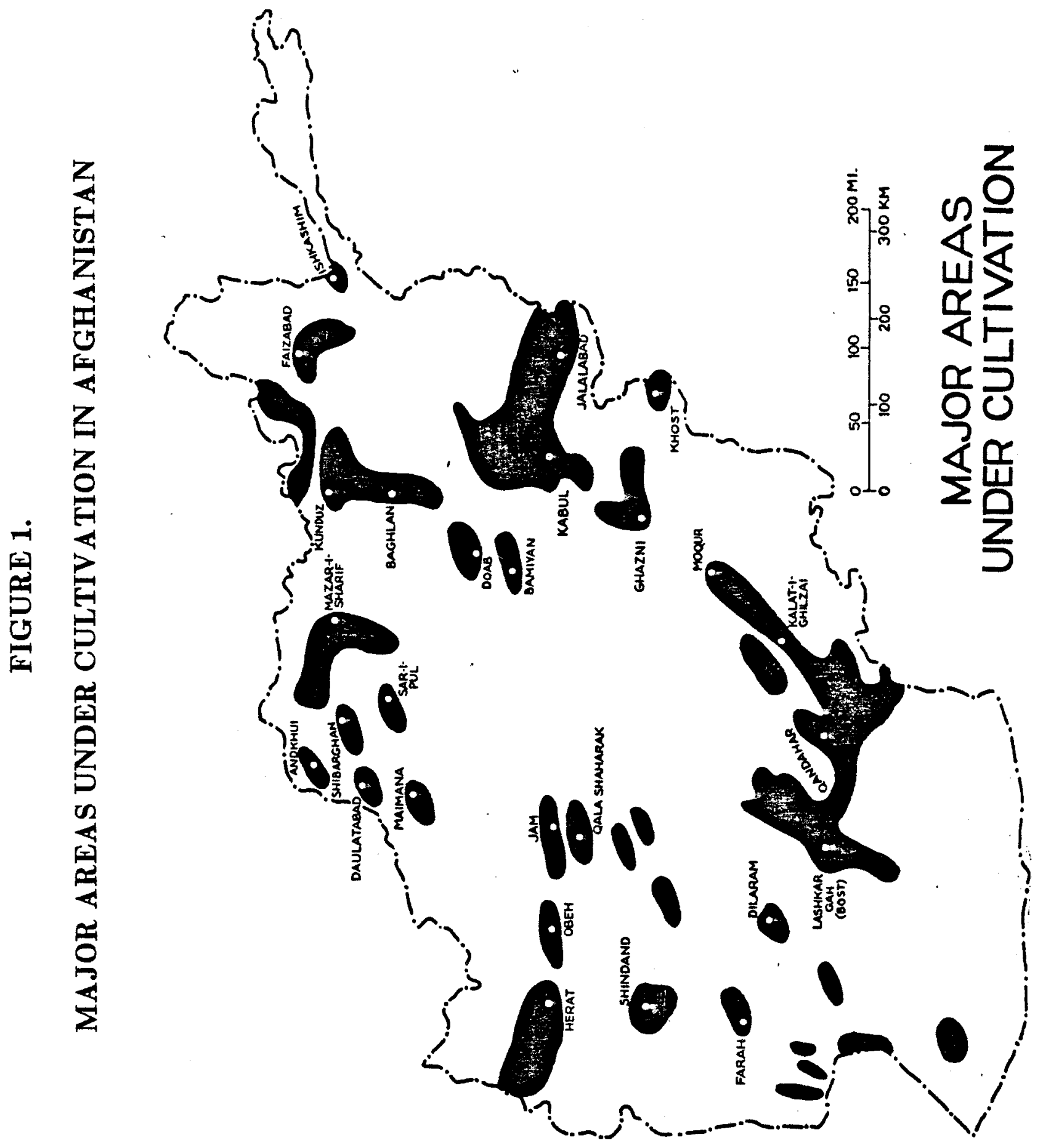


Z⿱

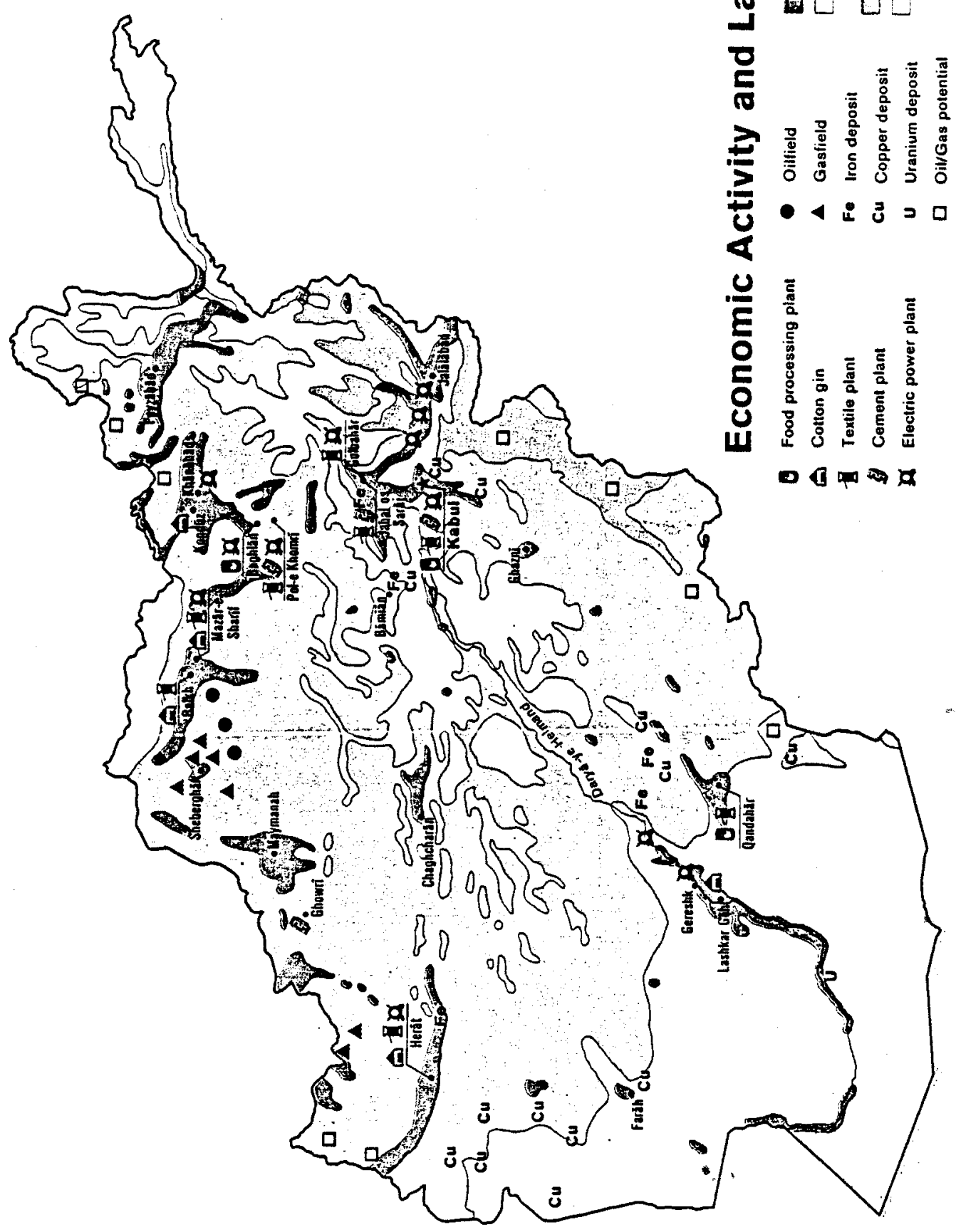


outside assistance is more complicated. Because a random or stratified random sample is impractical only a reflexive design would work. That is, data on specific recipients of assistance would have to be gathered over time on an individual family-by-family level. The difficulty of implementing this approach precludes its consideration at this time. ${ }^{2}$

In summary then, regardless of the method of data gathering employed, it is safe to conclude that it is feasible and practical to develop a management information system which will estimate the overall state of agricultural conditions in rural Afghanistan and the effects of war activity upon those conditions. However, it is not feasible and practical to demonstrate the effect of any outside assistance at this time.

The approach recommended by this consultancy is one which will improve both the quality and usefulness of the data as the project develops. In the initial phase only data from the refugee camps will be available. In the absence of adjustments they must be viewed as biased. Initial comparisons of agricultural conditions over time must be based only on recall-a very inaccurate data source.

In the next phase (interviews in Afghanistan), information will become available which allows for statistical adjustment of biases but initially comparisons over time will still have to be based upon recall only. However, as time passes, longitudinal trends will be determined from repeated interviews of current conditions-a very reliable source of evidence. $^{3}$ Because it is proposed that all data are in a database management system (DBMS), current status and trend analyses can be easily performed with whatever data exist at the time.

Table 1 presents a list of the data recommended to be gathered at the household level. They are identical to the data gathered by Azum Gul in 1982 except for the addition of time series data on family composition, climatic conditions and war effects. The Azum Gul survey is shown as Appendix B. Table 2 presents the recommended categories of data to be gathered at the community level from the local leader and by direct observation of the interview team.

${ }^{2}$ Establishing a database management system (DBMS) which could accommodate a different design variation two years from now could facilitate an eventual linkage with the Commodity Export Program and provide one of the necessary elements for an end user evaluation of that program.

${ }^{3}$ At this time it is unclear whether resurveys will be in individual families or in the same community. The research design should accommodate either alternative until it is determined from experience which option is practical. 
Table 1. Household-Level Data

1. Location: Province, District, Agricultural sub-region, village

2. Date and cause of immigration (if any)

3. Landholdings: owned, inherited, bought, distributed, tenant sharecropped, uncultivated

4. Farm employment: full time, part time

5. Family composition

6. Crop information (for each crop grown up to 5):

Acreage cultivated

Land preparation: open, tractor, manual

Seed availability: where purchased, price, amount

Fertilizer: where purchased, price, amount

Pesticides: where purchased, price, amount

Irrigation water: source, shortage, if any, cause

Yield:

Amount sold:

Damage cause: disease, birds, rodents, military, comments

7. Number of farm animals: oxen, cows, chicken, sheep, other

8. Amount of credit from government

9. Crops purchased: by crop, amount and price

10. Amount of military activity

11. Estimate of growing conditions in relation to "normal" year

(Items 3-11 would be gathered for the current harvest and for the year 1978.)

\section{Table 2. Community-Level Data}

1. Location: province, district, agricultural sub-region, village

2. Population: families, individuals

3. Estimate of number who have immigrated since 1978

4. Climatic conditions for current year

5. Description of agricultural disruption in village

a. direct military effects

b. indirect military effects 


\section{FEASIBLE OPTIONS FOR GATHERING DATA}

In light of the constraints described in the previous section, several different options for gathering data were considered. We present a brief synopsis of them below so that if a reframing of the objectives of the data system is considered at a future time, consideration can be given to an alternative option.

\section{Option 1. Gather Data from Refugee Camps Only}

This option would employ essentially the same procedures as used in the Azum Gul report. Methodology could be improved by adding two questions concerning degree of war activity and climatic conditions relative to the norm. Advantages include costs which are substantially less than the preferred option, a reduced time schedule and danger avoided by sending teams into Afghanistan. Disadvantages are (1) reduced credibility in the European community due to no interview occurring in Afghanistan, and (2) only marginal evidence on war effects, climatic deviations and productivity.

\section{Option 2. Implement the Original Plan without Modification}

This plan calls for interviews from refugee camps and sending teams into Afghanistan to collect comparable data in order to compare (validate) results. Technical assistance in procuring and coordinating three non-US experts is provided by a consulting firm. These consultants are experts in the areas of Agricultural Economics, Computers, and Survey Team training. Advantages include increased credibility of the results in comparison with the first option while disadvantages include higher cost and potential for fractioning responsibility among the TA (technical assistance) team.

\section{Option 3. Implement Original Plan but with Modified Technical Assistance}

This option employs interviews in both refugee camps and in Afghanistan, with minor modifications, but significantly changes the nature and amount of technical assistance. Advantages in comparison to Option 2 are lower cost, probably better coordination, and faster analysis turnaround time. The disadvantage is imposing more stringent capability demands upon the provider of technical assistance.

Because this is the recommended option, the technical assistance portion of this option is further detailed in Section IV of this report. 


\section{Option 4. Gather Data from Afghan Medical Workers Currently Interacting with the} Swedish Committee

An entirely different source of information would be the medical workers who return from Afghanistan to Pakistan in order to be resupplied with medicines and supplies. Presently they are interviewed by the Swedish Committee staff in order to determine the most appropriate level of resupply. A separate schedule could be administered to them about agricultural conditions in the regions in which they work. Alternatively, they could be provided with a schedule to fill out at the site of their medical practice and a stipend for this extra work. During 1985 there were slightly over 1,000 resupplies, so that even with a very high attrition rate (approximately 40\%), time series data could be obtained in many specific locations-even if only a fraction participated. Advantages include reduced cost and the opportunity of eventual integration between health and agriculture. Disadvantages include possible distraction from primary duties and the introduction of selection biases due to dropout which would have to be accommodated in the research design.

\section{Option 5. Gather Data from Mujahideen Commanders Who Visit the Swedish Committee}

During the course of a year approximately 40 mujahideen commanders visit the Swedish Committee in Peshawar. These commanders could be interviewed in a manner similar to that described in Option 4. Advantages include low cost and the disadvantages include those described in Option 4. An additional disadvantage, however, is that certain responses would be viewed as self-serving, resulting in additional biases.

\section{Option 6. Gather Data Only from the AID Supported Programs Currently nnder Implementation}

In this option, programs such as Afghanaid's Cash-for-Food, other PVO programs, and the Commodity Export Program would be provided with an interview schedule covering the conditions found at the site of assistance. While this alternative normally has distinct advantages, in the case of the Cross Border Humanitarian Assistance program, these advantages do not exist at this time. Afghanaid Cash-for-Food assistance reaches fewer than 10,000 families in only one of the 28 provinces. These families are themselves highly clustered in a small number of sites, restricting the information domain even further. In addition, the program design would have to be radically altered in order to make interviewing possible.

The Commodity Export Program has not yet begun and at present there are no plans for end-use accounting in the program except for sample verification of commodity movement. For this reason, there is no practical method for obtaining useful information during the next 18 months. However, it is strongly recommended that if one of the prior 
options is selected, that steps be taken to link these programs together in the future.

\section{Recommended Option}

This consultancy recommends the adoption of Option 3 because it has the highest likelihood of fulfilling both the objectives state in Section I: 1) to determine which regions in Afghanistan have the greatest need, and 2) to provide credible information to European donors so that they can make informed decisions. It is the purpose of the next section of this report to describe a system for handling data which, if applied to this option, will both reduce costs and increase timeliness and usability.

\section{DATA HANDLING AND ANALYSIS}

The characteristics of an ideal data handling and analysis system for the information gathered under Option 3 above is presented below. For the purposes of procuring technical assistance in implementing a system, these characteristics could be the basis for specifying the timing and nature of the tasks to be undertaken.

A. Information derived from questionnaires or other sources should be entered into a data handling system immediately upon completion of the questionnaire. In the case of Option 3 the system should accept questionnaire responses preferably within 24 hours of the interview. The reason for this short time is to provide the opportunity for correcting any clearcut errors which occurred during the administration of the questionnaire while the interviewers are in the field. The timing implication is that whatever system is utilized, it should be in operation by the time the interviews begin in the refugee camps.

B. The data handling and analysis system should use a relational database management system (DBMS). If properly utilized, such a system permits data to be manipulated in virtually any form desired. Subsets of data can be regrouped and/or reorganized to accommodate different analysis needs. As time progresses and other types of information are desired, the system can be reformatted and expanded to accommodate these changes. This system characteristic is especially important where it is unknown what future information and analysis needs will be.

C. The database management system (DBMS) should be utilized to detect and correct errors at the time at which data from the questionnaire are entered into the system. Because there is typically such a high error rate in recording, transcribing and keying data, it is extremely helpful to utilize the system to detect errors and provide opportunity for correction. In recent years, especially in the last six months, major 
strides have been made by software firms in simplifying the formatting of data entry into such database management systems. Consequently, schemes which utilize range limits and logical consistency checks are now much easier to implement. As a variable observation is keyed into such a system, the computer can perform a check to see that the value is within predefined allowable limits. In addition, logical consistency checks can be made with other variables already entered or which will be entered later in the schedule. For instance, the total acreage farmed should normally equal the sum of acreage farmed for each crop, or the number of individual family members should total to the family size. Similarly, men should not be pregnant nor should 70-year-old women be breastfeeding. In some cases the "error" detected by such logic checks is more a "likelihood of error" rather than a definite one. Data-entry formats can flag suspicious observations which then can be treated individually.

D. Employ computer hardware and software which is both adaptable and flexible. In 1986 changes in hardware and software are occurring at such a rapid pace that what is ideal today is considerably less so six months later. That is not to say, however, that an older system is obsolete. The important characteristic of both hardware and software is that it be amenable to updates as time goes by. Unfortunately it is a fact of life that this characteristic implies utilizing major supplies especially in the developing world where service is sparse.

DBMS software has been available on mainframes for about 15 years and on microcomputers for 8 years. However, systems which have relational characteristics, the ability to accommodate large numbers of variables and observations, and which employ easily programmed data entry procedures are quite recent. For instance, there is considerable difference between the DBMS program DBaseIII and the newly released DBaseIIIt. It is therefore very important that whoever provides the technical assistance in this area be currently using the most recent software. Otherwise considerable time and money will be wasted in obtaining an inferior product.

A cautionary note should be made concerning the so-called integrated software programs such as Symphony. These programs which provide word processing, a spread-sheet, a DBMS, and sometimes other features, such as statistics, graphics, and communications, are useful in some situations. However, the "price" for this integration is less powerful individual elements. It is recommended that they not be used for this system.

E. The data handling and analysis system should be capable of on-site analysisespecially during the early stages of implementation. One of the nicest features of a relational DBMS is that it facilitates analysis of subsets of data. These subsets can be 
small groups of variables for which there is a complete set of observations or they can be subsets of observations. Because simple analysis is so easily implemented, useful preliminary results can be forthcoming shortly after the initiation of data entry. While caution must, of course, be exercised when interpreting these preliminary results, they are nevertheless often very useful. In the case of this project three purposes would be served by such initial analysis. First, there may be insights which could facilitate AID programming decisions. Second, initial results will help in finalizing the protocol for the Afghanistan portion of the survey. Finally, some types of errors can only be caught after the initial stages of analysis. If these errors are detected early there is an opportunity to correct protocol while the initial survey is still in progress.

F. Provide for some level of hardware and personnel redundancy. Even though major strides have been made in improving hardware reliability, typical field settings are hard on equipment and system "crashes" are inevitable. Today, hardware redundancy does not come at a high price because of the dropping costs of equipment. Depending upon the configurations, at least two and preferably three computers should be available in Peshawar.

Because computer handling capability is scarce in Pakistan, especially among Afghans, it would be wise to train and employ at least three Afghans. One of the most promising aspects of this entire project is the enthusiasm of both the Swedish Committee director and the AID regional officer in participating in the analysis. Both have expressed strong interest in participating in an on-site "hands-on" training program which would allow them to utilize the data immediately upon receipt. It is therefore suggested that a phased training program be considered for inclusion in the technical assistance.

G. Ensure that technical assistance personnel have experience in DBMS design, data entry, programming, questionnaire formatting, and analysis procedures. It may seem that to expect all of these strengths in one individual is asking too much. However, any TA staff person who has been directly involved in the implementation of system in the field will have necessarily dealt with all of these topics. To specify all strengths ensures that the individual has both the technical knowledge and experience.

The reasons for recommending these capabilities in one person are many. DBMS specifications should be based upon the type of analysis to be performed. Questionnaire formatting should be specified according to data entry protocol and vice versa, the training of surveyors should reflect data entry procedures, and analysis software and procedures should accommodate both the DBMS and the questionnaire coding. In short, there are too many interrelated linkages between the tasks to have 
them performed by different individuals, especially for a small-scale effort such as this one.

Another reason for demanding direct experience in a field setting in the developing world is that there is a myriad of small but very significant "tricks-of-the-trade" that need be learned only once. Learning them the hard way for the first time can easily increase costs and time frames.

\section{Implementation Considerations}

As the design of this project has evolved, the magnitude, and more important, the nature of the technical assistance has changed. The project has always envisioned institution building as a very important element. Now the notion of institution building has devolved to more emphasis on on-site analysis capability using flexible and adaptive hardware and software. Quick turnaround time between data gathering and analysis has become even more important than before.

The methodology and approach propose in this report will result in a very rapid turnaround time between data gathering and initial analysis, i.e., two months. The phasing, timing, and budget considerations are, of course, all interrelated and are the subject of the next section in this report. 


\section{PHASING, TIMING, AND BUDGET CONSIDERATIONS}

The phasing, timing, and budget considerations are based upon which data gathering option is selected and how data handling and analysis is implemented. Figure 3 presents a Schedule of Project Tasks ordered by time to be performed by the Technical Assistance Contractor(s), assuming the recommendations in this report are accepted. Because it is presently unclear when the project will begin, the schedule is presented by month number. It must be kept in mind, however, that Task 10, administer the Afghanistan survey, can only be implemented during certain times of the year. If approved, the Swedish Afghanistan Committee proposes to undertake the Afghanistan interviewing, beginning in June 1987.

It is important to note that while the public document which is intended to meet the informational needs of European and other donors is not scheduled for completion before Month 18, the first rapid feedback reports will become available two months after the beginning of the interviews in the refugee camps and seven months after the beginning of the project. With trained staff on-site, who have gone through the first cycle of report generation using the DBMS and analysis system, subsequent rapid feedback reports can be generated at will. The frequency and scope would only be limited by the data which are available and the interests of the implementors.

Employment of a European Agricultural Economist to develop the research design, survey instruments and then to prepare a comprehensive report on agriculture conditions in Afghanistan is a critical component of the study. We envision this individual working closely with the implementors of the data handling and analysis system.

The estimated cost of implementing the Swedish Afghanistan Committee's proposal for data gathering is approximately $\$ 190,000$. It is important to recognize, however, that this cost includes what could be the first phase of institutionalizing a broad-based and broadly supported data gathering and analysis capability.

While technical assistance which would merely assist in analyzing the data from refugee camps could be provided for less than $\$ 30,000$, the usefulness of the exercise is questionable for all of the reasons mentioned earlier in this report. An estimate of costs for implementing all tasks in the project as described in Figure 3 is approximately $\$ 370,000$. 


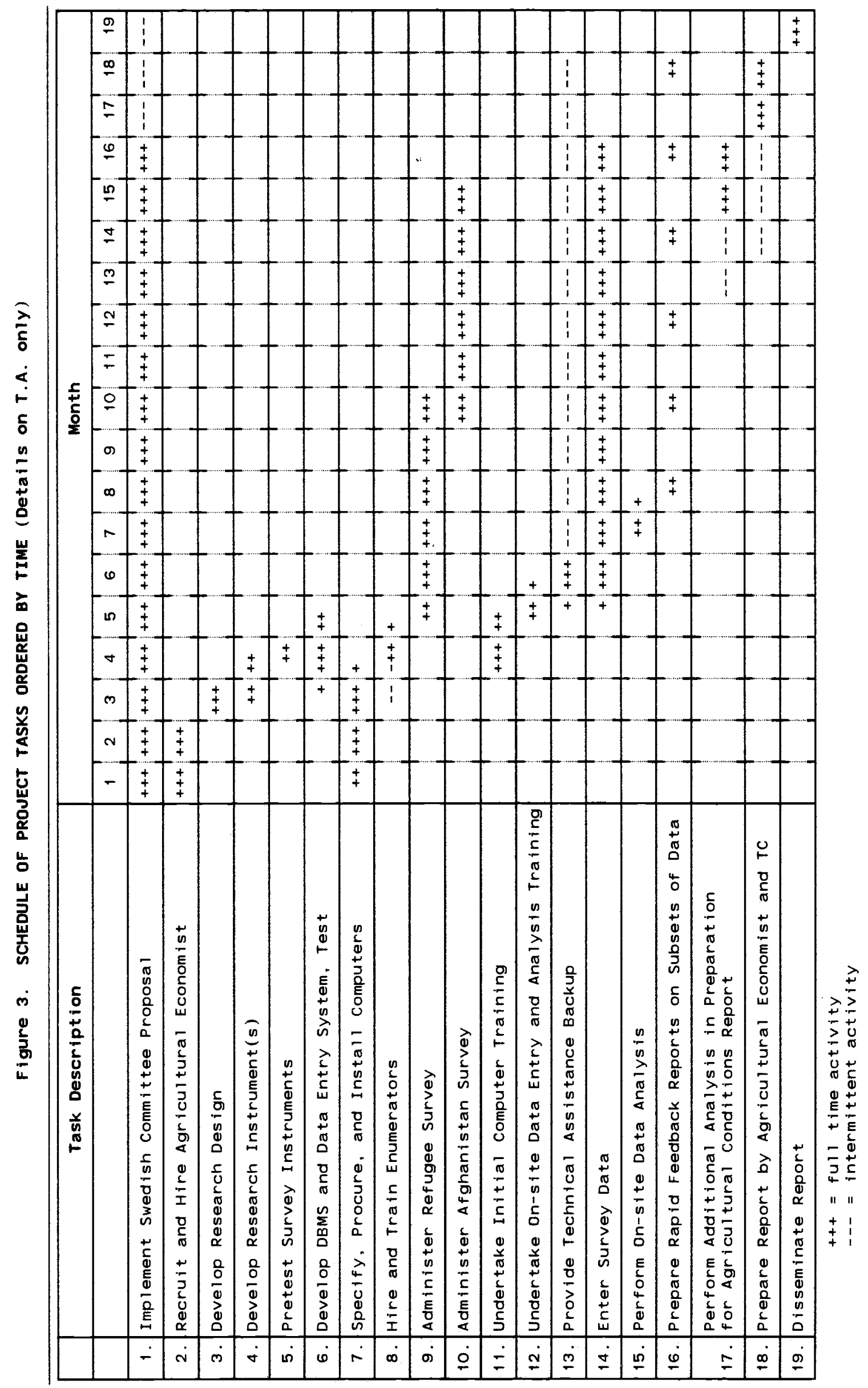




\section{APPENDIX A-REFERENCE MATERIALS}

1. "1986 Afghan Agriculture Survey-A Project Proposal," Swedish Committee for Afghanistan, 1986.

2. "Activity Approval Memorandum Commodity Export Program" (draft), by J. Wes Tribble, Edward Caesar, and Thomas Bucci, American Manufacturers Export Group, Houston, 1986.

3. "Initial Questionnaire Prepared for Survey of Afghanistan Refugees" (draft), by Noory Mohammad Arif, 1986.

4. "Food Shortages in Afghanistan," Azum Gul, March 1983.

5. "Proposal for an Emergency Cash for Food Programme to Northern Afghanistan (3 areas)," Afghanaid, London, 1986.

6. "Survey Guidelines: (1) Information to be Collected by Afghan Medical and Educational Personnel Inside Afghanistan, (2) Jihad." Louis Dupree, 1985.

7. "The Threat of Famine in Afghanistan," Frances D'Souza, International Disaster Institute, London School of Hygiene and Tropical Medicine, University of London, May 1984.

8. Emergency Cash-for-Food Programme 1985-86, Project Report, Afghanaid, 18 Charing Cross Road, London, October 1985.

9. Afghanistan, Louis Dupree, Princeton University Press, 1980. 
APPENDIX B AZUM GUL SURVEY OF 1982 
I. Vij.line Vistrict. proviner.

2 Mo. of persems in the fomily,

3. Tims of immicration t:o nalijstan"

4 rausic of immination

5. Lainit ownershin (a) Acrencic (herilus) in 1.975 1931 19832

(b) Inherited

(c) lought:

(d) Throurgh Land Reform (c) Tenant:

\section{8}

6. Hro.nf riersons working on

the farm

Fulltime

rart tine

7.. Crons aroun on the farm

A. Wheat.

Acrearie (Terihs)

Land preparation

(oxen-t)actor etc.)

secd availahle

(local or reed co.)

where was it bounht:?

frice

srount of fertiliser used ( $n=x$ Jerib)

where was it bought?

nrice

rmount of mesticir?e usint (snecify)

where was jt fourlit?

price

Irriation water source .. River - Karez inell Enoiugh -

Shor tage (molerate/sevrre) 
Ciause of water shortare (if any)

Cron damauc (if any) Discase (qiven as percontate)

$$
\begin{aligned}
& \text { Mird: } \\
& \text { Military } \\
& \text { Rodents }
\end{aligned}
$$

Average yicld (Seors/Jerib)

D. (Crop)

Acreago

Anount of fertiliser used (per Terib)

Pcsticides used (specify)

Irriçation water. Source - piver Enougls

shiortaue (moderate/severe)

Cause of water shortange

Crop damaye (if any) Disease (given as percentage) Birds Military Rodent.s

Further coments on crop damage

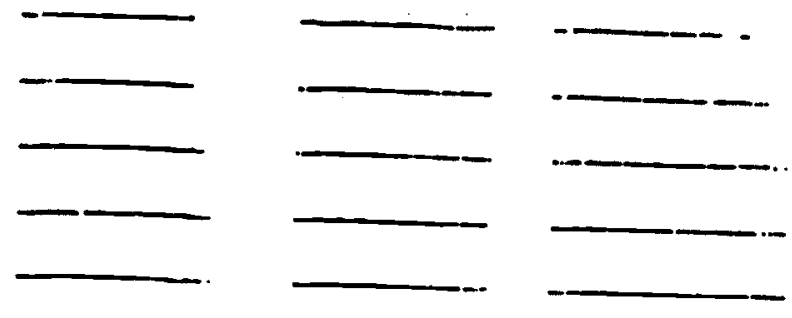
, Karez Wa1
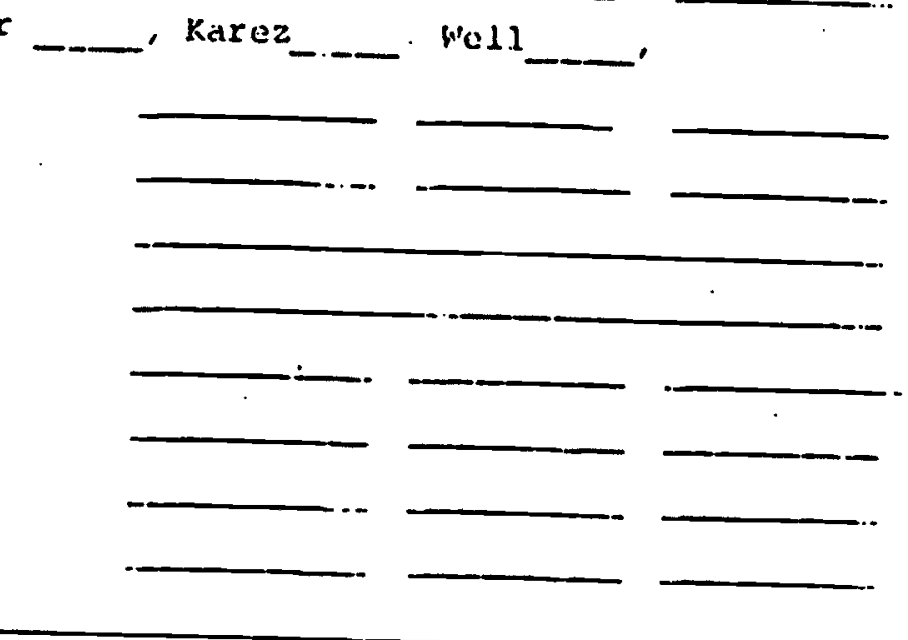

Averane yield(Scers/Jerib)

E. (Cron)

Acreage

Amount of fertiliser used (ner Jerih)

Pesticides used

(snecify)

Irxigation water: Source - Rlvor !nourh .

Shortaqe (morlerate/severn)

Cause of water shortarle 
riallse: of wiltos shortace (ir any)

$1979 \quad$ 19!!

Aueraue yjela (secrti/terili)

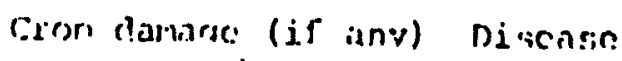

liirris

Military

korlents

B. Cnrn

Acreacte (i.jeribs)

srount of fertiliser used

(nor Teril:)

ravernment or local source

Drice

Amount: of resticides usex (snocify)

reivernment or locil source

price

Irrjotion water source - River

bisoug̣lı

Sthortane - (moderate/scuere)

Cinse of rater shortann (if anv)
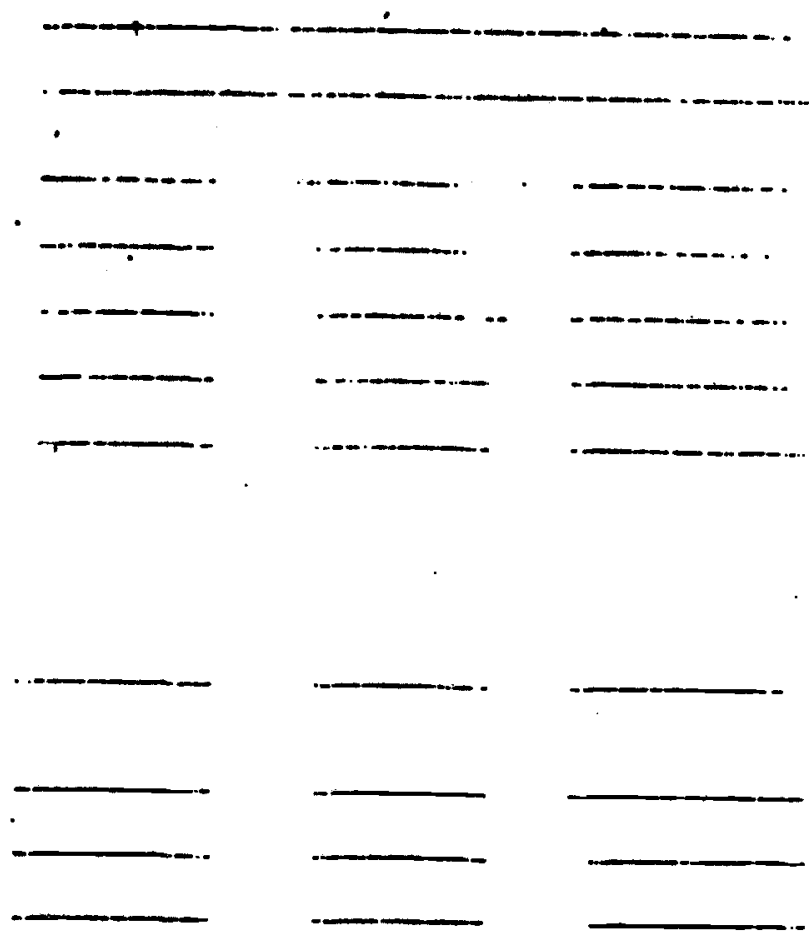

Causc or water shortang (if anv)

Cron damane (if ariy) biscase

(riven ass percentisne) Birds

\section{Military}

Averane yinld (Secrs/Jerib)

C. Rireg

Acreage

Amount of fertilispr used

(mor Terils)

nesticinles used

(smecify)

Irrimation witer rource - niver

Fnourh

Shortane (morlerate/scvere)
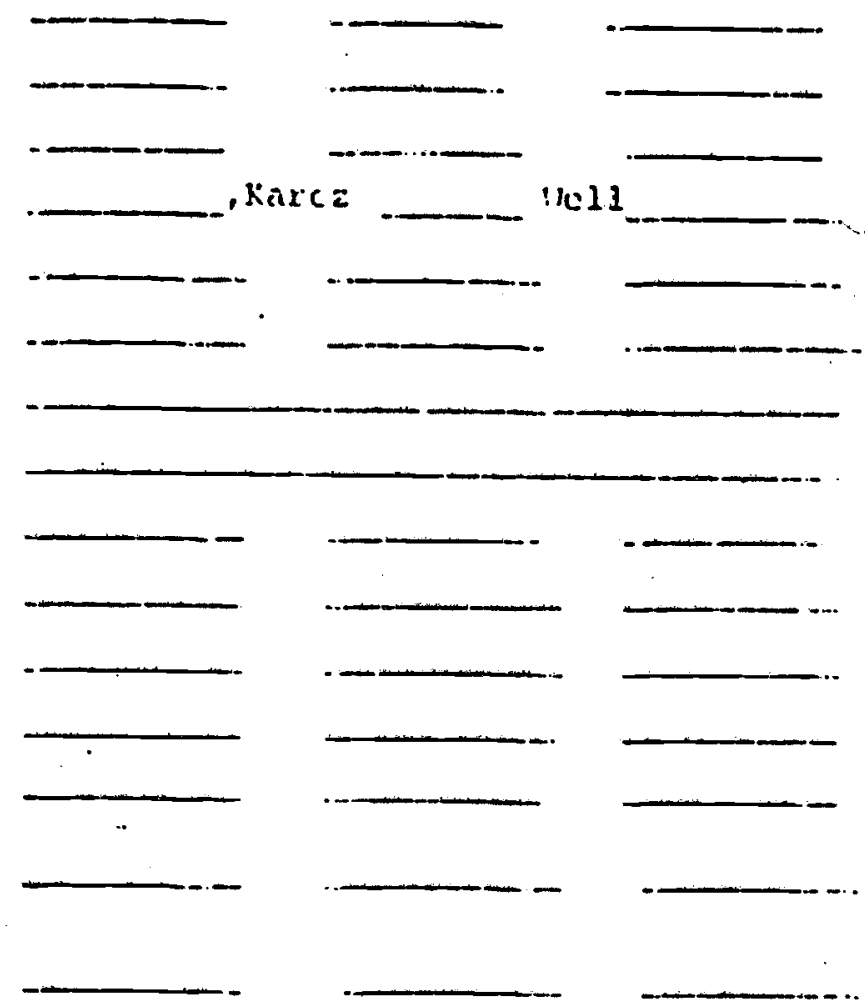


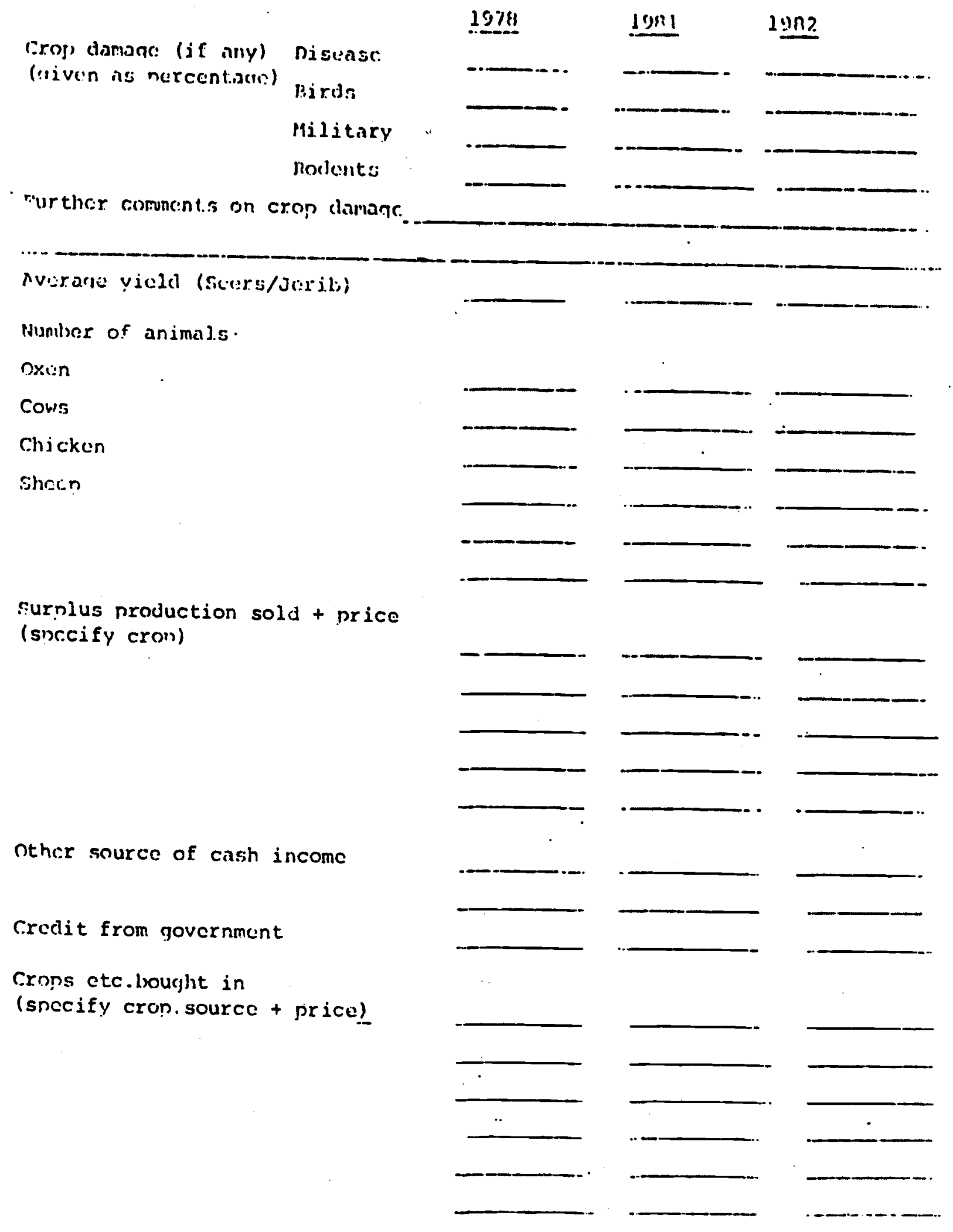

10. Other source of cash income

11. Credit from governmunt

12. Crons etc.hought in (snceify cron. source + price)

13. Snccific problems associated with farning not mentioned in tho interviw from ahnur. 


\section{APPENDIX C PERSÖNS CONTACTED}

In the Office of the AID Representative for Afghanistan Affairs:

Al Nehoda, Regional Officer, Northwest Frontier

Val Mahan, Project Officer, CEP and Education

John Gunning, Program Officer

Carol Scherrer-Palma, Project Officer, Health

Susan Hase, Office Manager

In the U.S. Embassy:

Virginia M. Test, Computer Systems

In the Swedish Afghanistan Committee:

Anders Fange, Director

Noory Mohammad Arif, Agricultural Expert

In the Office of Evaluation-ANE-Washington:

Maureen Norton

Sharon Pines

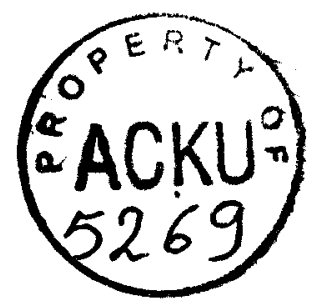

